\title{
Retraction
}

\section{RETRACTED ARTICLE: The food industry and conflicts of interest in nutrition research: A Latin American perspective}

\author{
Joaquin Barnoya ${ }^{a, b, *}$, and Marion Nestle \\ ${ }^{a}$ Research Department, Unidad de Cirugia Cardiovascular de Guatemala, \\ 5a Av 6-22 zona I I, Guatemala oror I, Guatemala \\ ${ }^{\mathrm{b}}$ Division of Public Health Sciences, Department of Surgery, Washington University in \\ St. Louis, 660 S. Euclid Av., St. Louis, MO 631 I0, USA \\ ${ }^{c}$ Department of Nutrition, Food Studies, and Public Health, New York University, \\ New York, USA \\ *Corresponding author.
}

Journal of Public Health Policy advance online publication, I I December 20I 5; doi:IO.IO57/jphp.20I 5.45

Retraction to: Journal of Public Health Policy (2015). doi:10.1057/ jphp.201 5.37; published online 29 October 2015

The Authors, Editors and Publisher, following complaints from two parties, Edward Fischer and Carolina Siu Bermúdez, have investigated the circumstances around the publication of the Viewpoint entitled 'The food industry and conflicts of interest in nutrition research: A Latin American perspective' by Joaquin Barnoya and Marion Nestle (2015) (available at www.palgrave-journals.com/jphp/journal/vaop/ ncurrent/full/jphp2or 537a.html), which published online in the journal on 29 October 2015. The findings below are sufficient cause to retract the article and readers are advised that it should no longer be cited from the Journal of Public Health Policy. 
The Editors' investigation into the complaints has revealed the following:

I. The Authors failed to disclose a competing interest when they submitted the manuscript. As the Viewpoint is, among other things, about the role of the Central American Nutrition Institute (INCAP), failing to disclose the relationship between Dr Barnoya and INCAP (as Principal Investigator on a training grant for which INCAP was the recipient institution) was a serious omission.

2. The Viewpoint includes an incomplete and inaccurate reference. The inaccurate citation is material, as the authors intended the whole argument presented in the Viewpoint to rely exclusively on the Advertorial cited as reference \# $\mathrm{I}$. A correct reference would read as follows: Alianza Contra la Desnutricion. elPeriódico. 23 July 20I 5 ; Advertising: 9; this might have been supplemented with a subtitle to read: ALIANZA CONTRA LA DESNUTRION: INCAP, $c b c y$ Fundación Shalom firman convenio de cooperatión. (ADVERTORIAL). The authors may have compounded readers' potential confusion by failing to cite the Advertorial later in the Viewpoint where they base their statements solely on their understanding of the Advertorial.

3. The authors presented and now acknowledge a factual error. Their statement in the Viewpoint that "the Central American Bottling Corp... . is involved in the manufacture and distribution of Manì+" is not correct.

4. Characterizations by the authors based solely on the Advertorial and not cross-checked against other sources for accuracy could mislead readers to reach erroneous conclusions, for example, about the role of INCAP (it did not receive any funding from cbc), or about cbc's role in distributing Maní (it purchased the product, but did not have any other role in distribution).

Despite the serious failures of rigor and precision, the Editors find no persuasive evidence that the Authors intended to harm the reputation of Manít or INCAP and the authors would like to apologise for the lack of clarity and errors in the Viewpoint.

The Authors as well as Edward Fischer and Carolina Siu Bermúdez have requested this retraction. 
Please see Palgrave Macmillan Journals Ethics Policy at www. palgrave-journals.com/pal/authors/ethics_policy.html.

Electronic supplementary material The online version of this article (doi:Io. I057/jphp.20I 5.37) contains supplementary material, which is available to authorized users. 